Trinity University

Digital Commons@ Trinity

Chemistry Faculty Research

Chemistry Department

$10-19-2005$

\title{
Charge-Mediated Recognition of N-Terminal Tryptophan in Aqueous Solution by a Synthetic Host
}

Meghan E. Bush

Trinity University

Nicole D. Bouley

Trinity University

Adam R. Urbach

TrinityUniversity, aurbach@trinity.edu

Follow this and additional works at: https://digitalcommons.trinity.edu/chem_faculty

Part of the Chemistry Commons

\section{Repository Citation}

Bush, M. E., Bouley, N. D., \& Urbach, A. R. (2005). Charge-mediated recognition of N-terminal tryptophan in aqueous solution by a synthetic host. Journal of the American Chemical Society, 127, 14511-14517. doi: 10.1021/ja0548440

This Post-Print is brought to you for free and open access by the Chemistry Department at Digital Commons @ Trinity. It has been accepted for inclusion in Chemistry Faculty Research by an authorized administrator of Digital Commons @ Trinity. For more information, please contact jcostanz@trinity.edu. 


\title{
Charge-Mediated Recognition of N-Terminal Tryptophan in Aqueous Solution by a Synthetic Host
}

\author{
Meghan E. Bush, Nicole D. Bouley and Adam R. Urbach* \\ Department of Chemistry, Trinity University, San Antonio, TX 78212 \\ * To whom correspondence should be addressed: aurbach@trinity.edu
}

Abstract. The molecular recognition of peptides and proteins in aqueous solution by designed molecules remains an elusive goal with broad implications for basic biochemical research and for sensors and separations technologies. This paper describes the recognition of $\mathrm{N}$-terminal tryptophan in aqueous solution by the synthetic host cucurbit[8]uril (Q8). Q8 is known to form 1:1:1 heteroternary complexes with methyl viologen (MV) and a second aromatic guest. Here, the complexes of $\mathrm{Q} 8 \bullet \mathrm{MV}$ with (i) the four natural aromatic $\alpha$-amino acids, (ii) four singly charged tryptophan derivatives, and (iii) four tryptophan-containing tripeptides, were characterized by isothermal titration calorimetry, mass spectrometry, and UV-visible, fluorescence, and ${ }^{1} \mathrm{H}$ NMR spectroscopy. We find that $\mathrm{Q} 8 \bullet \mathrm{MV}$ binds Trp-Gly-Gly with high affinity $\left(\mathrm{K}_{\mathrm{a}}=1.3 \times 10^{5} \mathrm{M}^{-1}\right)$, with 6-fold specificity over Gly-Trp-Gly, and with 40-fold specificity over Gly-Gly-Trp. Analysis of the nine indole-containing compounds suggests that peptide recognition is mediated by the electrostatic charge(s) proximal to the indole, and that the mode of binding is consistent for these compounds. Complex formation is accompanied by the growth of a visible charge-transfer band and the quenching of indole fluorescence. These optical properties, combined with the stability and selectivity of this system, are promising for applications in sensing and separating specific peptides. 


\section{Introduction}

The design of molecules capable of binding to predetermined sequences of amino acids in aqueous solution is an important problem in the chemical and biomedical sciences. ${ }^{1}$ An excellent body of work has been carried out in this area, ${ }^{1,2}$ and it is the surprising result of these studies that so few synthetic compounds bind peptides with equilibrium association constants $\left(\mathrm{K}_{\mathrm{a}}\right)$ greater than $10^{4} \mathrm{M}^{-1}$ and/or with considerable sequence specificity in purely aqueous solution. There is also significant interest in the development of synthetic compounds capable of a change in optical activity on binding to a specific peptide. ${ }^{3}$ One host that hints of great promise in addressing these problems is cucurbit[8] uril (Q8, Figure 1), ${ }^{4,5}$ which is the topic of this paper.

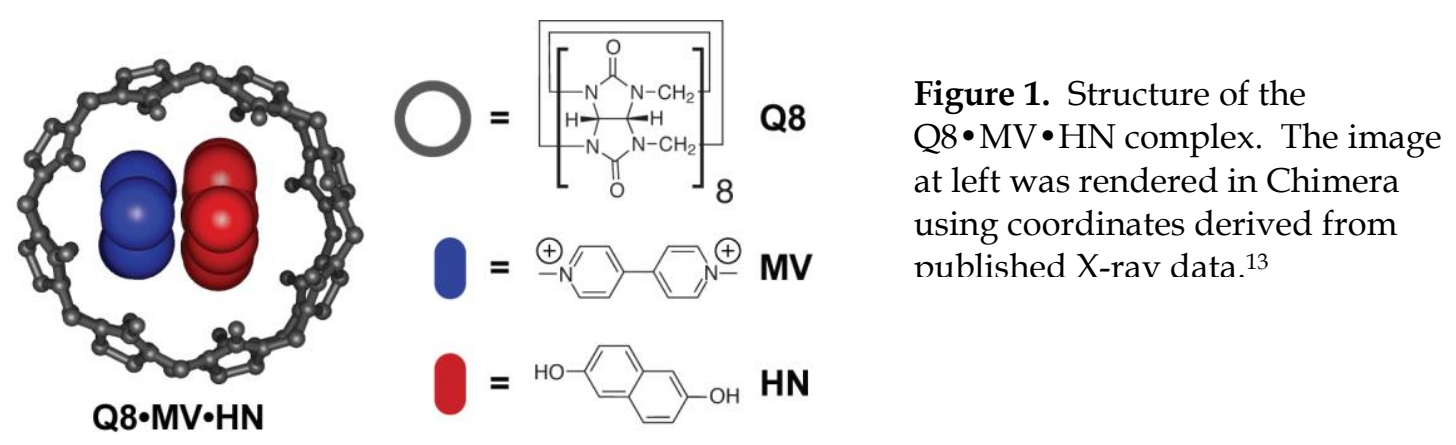

Q8 is the eight-membered, expanded macrocycle of cucurbituril (Q6). Q6 was discovered in 1905,6 and more recently found to bind amines and metal cations in aqueous solution with equilibrium association constants $\left(\mathrm{K}_{\mathrm{a}} \mathrm{s}\right)$ in the range of $10^{3}-10^{5} \mathrm{M}^{-1} .^{7} \mathrm{Q} 6$ and the other Qn homologues ${ }^{4,5}$ are synthetically 
accessible, ${ }^{4,8}$ donut-shaped molecules with a hydrophobic cavity and constricted portals fringed with carbonyl groups. This structure promotes binding to organic amines by including the hydrophobic portion of the compound inside the cavity while forming cation-dipole interactions between the positively charged ammonium groups and the carbonyl portals. The mechanism of Q6 complexation has been well characterized, ${ }^{9}$ but the scope of possible guests for Q6 is limited by its relatively small size.

Recently, a family of Qn homologues was discovered ${ }^{4}$ by Kim and coworkers that has greatly broadened the potential for this class of molecules in supramolecular chemistry. ${ }^{5}$ Q7 has the highest aqueous solubility among the Qn homologues, and the recognition properties of Q7 for cationic, aromatic guests have been explored extensively by the groups of Kaifer, ${ }^{10} \mathrm{Kim},{ }^{11}$ and others. ${ }^{12} \mathrm{~K}_{\mathrm{a}}$ values for the binding of Q7 to these guests are also in the range of $10^{5} \mathrm{M}^{-1}$, and although detailed mechanistic studies have not yet been carried out on Q7 or Q8, the observed patterns of binding indicate a mechanism similar to that of Q6. ${ }^{9}$

Q8 is fundamentally different from its smaller Qn homologues in that it can bind simultaneously and selectively to two different aromatic guests at low concentrations. ${ }^{13}$ For example, Q8 can bind to one equivalent of methyl viologen $(\mathrm{MV})$, and the $\mathrm{Q} 8 \bullet \mathrm{MV}$ complex can then bind to one equivalent of $2,6-$ dihydroxynaphthalene $(\mathrm{HN})$. Complex formation is driven by hydrophobic interactions and by the formation of a charge-transfer complex between $\mathrm{HN}$ and MV inside the cavity of Q8 (Figure 1). ${ }^{13}$ This system has been creatively used to 
construct a broad range of unique supramolecular architectures, ${ }^{14}$ and to catalyze specific chemistries. ${ }^{15}$ Remarkably, Kim and coworkers report that Q8 $\bullet$ MV can bind to other aromatic guests, such as tryptophan, tyrosine, and dopamine. ${ }^{16}$ Despite the many interesting studies involving Q8, however, no quantitative data have yet been reported on the stability of $\mathrm{Q} 8 \bullet \mathrm{MV}$ in complex with $\mathrm{HN}$ or with other guests.

Here we examine the potential for $\mathrm{Q} 8 \bullet \mathrm{MV}$ to recognize specific amino acids and peptides. The thermodynamic binding parameters and spectral properties were measured for twelve ternary complexes of the formula $\mathrm{Q} 8 \bullet \mathrm{MV} \bullet \mathrm{X}$, where $\mathrm{X}$ is the four aromatic $\alpha$-amino acids, four singly charged tryptophan derivatives, and four tryptophan-containing peptides. We find that Q8 $\bullet \mathrm{MV}$ binds tryptophan most stably among the aromatic $\alpha$-amino acids. Analysis of the series of singly charged tryptophan derivatives suggests that a positive charge near the indole increases binding affinity, and a negative charge decreases affinity. We hypothesized that this effect could be the basis for specific peptide recognition, where $\mathrm{Q} 8 \bullet \mathrm{MV}$ should bind $\mathrm{N}$-terminal tryptophan with higher affinity than C-terminal or internal tryptophan residues. Data on the series of tryptophan-containing peptides support this hypothesis and show that WGG is bound more tightly than GWG, followed by GGW. The spectral data consistently reveal the formation of a charge-transfer absorbance, the quenching of indole fluorescence, and the perturbation and broadening of NMR chemical shifts on binding. 


\section{Results and Discussion}

Q8 Solubility and Q8 $\bullet$ MV Stability. It is known that Q8 is poorly soluble in water and insoluble in organic solvents, ${ }^{5}$ and that Q8 binds tightly to MV in a 1:1 complex. ${ }^{17}$ As a quantitative basis for our studies on ternary complexes of Q8, it was important to measure the solubility Q8 and the stability of Q8•MV (Figure 2) in our solvent system, $10 \mathrm{mM}$ sodium phosphate, $\mathrm{pH}$ 7.0. The solubility of Q8 was determined by gravimetric analysis, measuring the residual mass of a known volume of saturated Q8 solution. The average value from three experiments was $0.13 \mathrm{mM}( \pm 0.09)$. Although the solubility of Q8 is weak, it improves significantly on binding to MV. The $K_{a}$ value for the formation of $\mathrm{Q} 8 \cdot \mathrm{MV}$ at $27^{\circ} \mathrm{C}$ is $8.5( \pm 0.3) \times 10^{5} \mathrm{M}^{-1}, 18$ as determined by isothermal titration calorimetry (see Supporting Information). The high stability of the $\mathrm{Q} 8 \bullet \mathrm{MV}$ complex ensures that a large fraction of complex is present at $\mu \mathrm{M}$ $\mathrm{mM}$ concentrations to bind to a second guest.

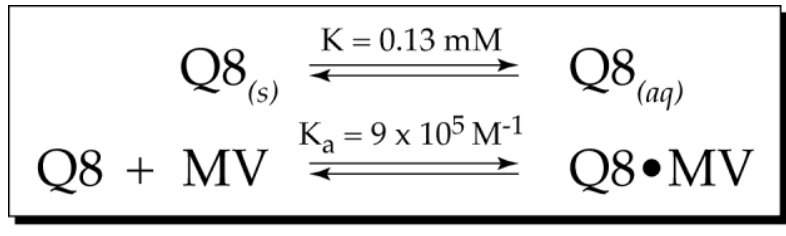

Figure 2. Measured values for the solubility of Q8 and its binding to MV in $10 \mathrm{mM}$ sodium phosphate, $\mathrm{pH}$ 7.0.

Binding of Q8 $\bullet \mathrm{MV}$ to the Aromatic Amino Acids. Kim and coworkers found that $\mathrm{Q} 8 \bullet \mathrm{MV}$ binds to tryptophan, tyrosine, and dopamine, as observed by 
the resulting changes in visible color and in their NMR spectra. ${ }^{5,16}$ As a foundation for studying peptide recognition by Q8, we wanted to confirm these findings and to quantitatively determine the thermodynamic parameters for binding. It is quite possible that $\mathrm{Q} 8 \bullet \mathrm{MV}$ binds to one or more of the aliphatic $\alpha-$ amino acids, but we focused on the aromatic amino acids for their advantageous optical properties and for the likelihood that any binding would be similar in nature to prior studies on $\mathrm{Q} 8 \bullet \mathrm{MV} \bullet \mathrm{HN}$, and therefore more straightforward to characterize.

We used isothermal titration calorimetry (ITC) to measure $K_{a}$ values (Table 1) for the binding of $\mathrm{Q} 8 \bullet \mathrm{MV}$ to the natural aromatic amino acids: tryptophan (Trp, 1), tyrosine (Tyr, 2), phenylalanine (Phe, 3), and histidine (His, 4). A 1:1 binding stoichiometry was observed in all experiments. The data show that $\mathrm{Q} 8 \bullet \mathrm{MV}$ binds $\operatorname{Trp}$ with highest affinity $\left(\mathrm{K}_{\mathrm{a}}=4.3 \times 10^{4} \mathrm{M}^{-1}\right)$ and with 8-fold and 19-fold specificity over Phe and Tyr, respectively. No binding was observed for His.

Table 1. Equilibrium Association Constants for Q8・MV with Aromatic Amino Acids

\begin{tabular}{ll}
\hline Guest & \multicolumn{1}{c}{$\mathrm{K}_{\mathrm{a}}\left(\mathrm{M}^{-1}\right)^{\mathrm{a}}$} \\
\hline Trp (1) & $4.3( \pm 0.3) \times 10^{4}$ \\
Phe (2) & $5.3( \pm 0.7) \times 10^{3}$ \\
Tyr (3) & $2.2( \pm 0.1) \times 10^{3}$ \\
His (4) & no binding observed \\
\hline${ }^{\mathrm{a}}$ Mean values measured from at least three ITC experiments \\
at $27^{\circ} \mathrm{C}$ in $10 \mathrm{mM}$ sodium phosphate, $\mathrm{pH}$ 7.0. Standard \\
deviations are given in parentheses.
\end{tabular}


If the formation of a charge-transfer complex were the primary driving force for binding, then one would expect tyrosine to bind more tightly than phenylalanine to $\mathrm{Q} 8 \bullet \mathrm{MV}$ on the basis of the more electron-rich phenol ring. ${ }^{19}$ This result was not observed. The data are more consistent with a model in which the relative binding affinity is governed by the hydrophobicity of the second guest molecule as it sheds some of its hydration shell on entering the Q8 cavity. In such a model, one would expect tyrosine and histidine to bind more poorly than tryptophan or phenylalanine.

\section{Effects of Electrostatic Charge on Tryptophan Binding. The high}

binding affinity and optical properties of tryptophan make it an attractive target for detailed studies of molecular recognition by Q8 $\bullet \mathrm{MV}$. While the size, shape, and hydrophobicity of the indole side-chain of tryptophan are similar to that of $\mathrm{HN}$, tryptophan is zwitterionic at $\mathrm{pH} 7.0$ and, thus, can have two proximal charges that may influence complex formation. One might expect the negative charge on tryptophan to attract to MV but repel from the carbonyl portal of Q8. Conversely, a positive charge could repel from MV but attract to the carbonyl portal of Q8. 


\section{$\underline{\mathrm{Q} 8} \bullet \mathrm{MV}+\mathrm{X} \rightleftarrows \mathrm{Q} 8 \bullet \mathrm{MV} \bullet \mathrm{X}$}

(a) $\mathrm{X}=$ Derivatives of Tryptophan

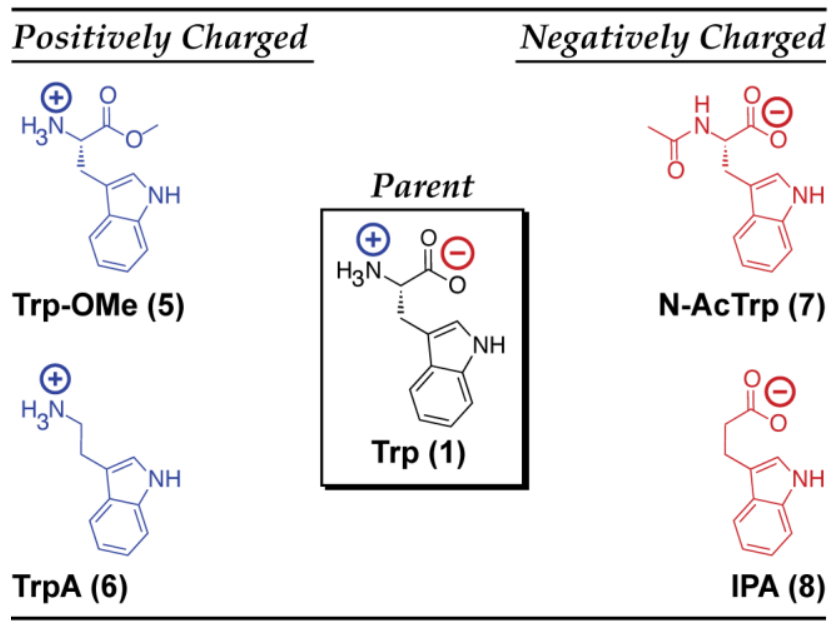

(b) $\mathrm{X}=$ Peptides of Tryptophan

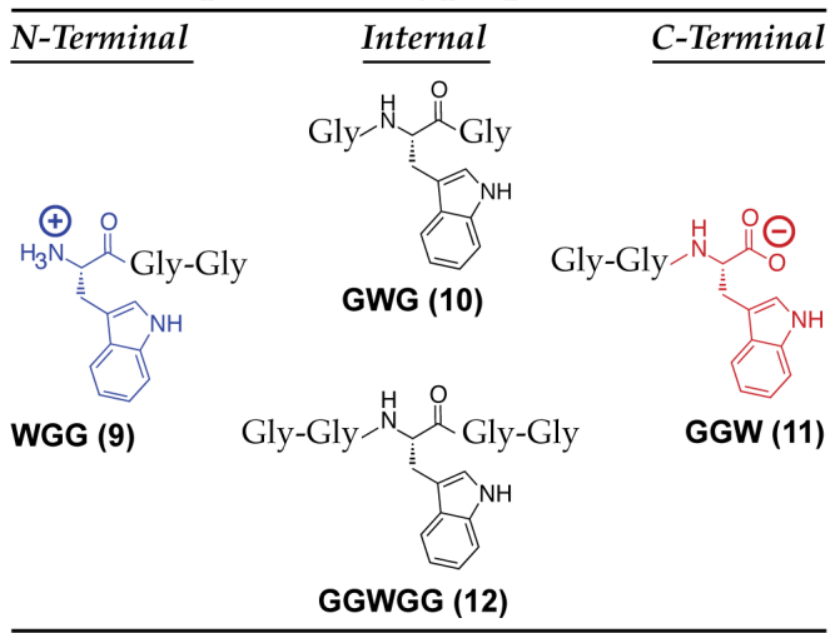

Figure 3. Series of monomeric tryptophan derivatives (a) and tryptophan-containing peptides (b) examined as guests for $\mathrm{Q} 8 \bullet \mathrm{MV}$. The series was designed to explore the hypothesis that $\mathrm{Q} 8 \cdot \mathrm{MV}$ can recognize specific peptides on the basis of the electrostatic charge proximal to 
negative charge. N-Acetyl tryptophan (N-AcTrp, 7) and indole priopionic acid (IPA, 8) lack a positive charge. TrpA and IPA are electrostatically analogous to Trp-OMe and N-AcTrp, respectively, but have less steric bulk.

ITC was used to determine the thermodynamic parameters (Table 2) for the binding of Q8•MV to Trp and its derivatives 5 - 8. A 1:1 binding stoichiometry was observed in all experiments. The ITC data show that Q8•MV binds Trp, Trp-OMe, and TrpA with $\mathrm{K}_{\mathrm{a}} \sim 5 \times 10^{4} \mathrm{M}^{-1}$ and with approximately 20 -fold selectivity over N-AcTrp ( $\mathrm{K}_{\mathrm{a}}$ $\left.=3.1 \times 10^{3} \mathrm{M}^{-1}\right)$ and IPA $\left(\mathrm{K}_{\mathrm{a}}=2.3 \times 10^{3} \mathrm{M}^{-1}\right)$. The presence of each ternary complex was confirmed by electrospray mass spectrometry (ESI-MS). All binding experiments were also carried out in the absence of Q8, and no indication of binding was observed; this result shows that binding affinity in the absence of Q8 is $<10^{3} \mathrm{M}^{-1}$. The binding data suggest that removal of the positive charge on Trp weakens its complex with Q8•MV.

Table 2. Thermodynamic Binding Data for Q8 $\bullet \mathrm{MV}$ with Derivatives of Tryptophan

\begin{tabular}{lccccc}
\hline Guest & & $\begin{array}{c}\mathrm{K}_{\mathrm{a}}^{\mathrm{a}} \\
\left(\mathrm{M}^{-1}\right)\end{array}$ & $\begin{array}{c}\Delta \mathrm{G}^{\mathrm{b}} \\
(\mathrm{kcal} / \mathrm{mol})\end{array}$ & $\begin{array}{c}\Delta \mathrm{H}^{\mathrm{c}} \\
(\mathrm{kcal} / \mathrm{mol})\end{array}$ & $\begin{array}{c}-\mathrm{T} \Delta \mathrm{S}^{\mathrm{d}} \\
(\mathrm{kcal} / \mathrm{mol})\end{array}$ \\
\hline Trp & $\mathbf{( 1 )}$ & $4.3( \pm 0.3) \times 10^{4}$ & $-6.4( \pm 0.1)$ & $-10.6( \pm 0.1)$ & $4.2( \pm 0.1)$ \\
Trp-OMe & $\mathbf{5})$ & $6.3( \pm 1.5) \times 10^{4}$ & $-6.6( \pm 0.2)$ & $-10.7( \pm 0.2)$ & $4.1( \pm 0.1)$ \\
TrpA & $\mathbf{( 6 )}$ & $5.4( \pm 0.2) \times 10^{4}$ & $-6.5( \pm 0.1)$ & $-12.2( \pm 0.3)$ & $5.7( \pm 0.3)$ \\
N-AcTrp & $(7)$ & $3.1( \pm 0.1) \times 10^{3}$ & $-4.8( \pm 0.1)$ & $-11.1( \pm 0.1)$ & $6.2( \pm 0.1)$ \\
IPA & $(\mathbf{8})$ & $2.3( \pm 0.4) \times 10^{3}$ & $-4.6( \pm 0.2)$ & $-12.7( \pm 0.4)$ & $8.0( \pm 0.5)$ \\
\hline
\end{tabular}


a Mean values measured from at least three ITC experiments at $27^{\circ} \mathrm{C}$ in $10 \mathrm{mM}$ sodium phosphate, $\mathrm{pH}$ 7.0. Standard deviations are given in parentheses. ${ }^{b}$ Gibbs free energy values calculated from Ka values. Standard deviations for $\Delta \mathrm{G}$ values were calculated as the relative error observed in $\mathrm{K}_{\mathrm{a}}$, due to their relationship by a natural logarithm. ${ }^{\mathrm{c}}$ Enthalpy values measured by ITC. ${ }^{\mathrm{d}}$ Entropic contributions to $\Delta \mathrm{G}$ calculated from Ka and $\Delta \mathrm{H}$ values.

Analysis of enthalpy and entropy values in this series (Table 2) reveals that complex formation is enthalpically driven $(|\Delta \mathrm{H}|>|\mathrm{T} \Delta \mathrm{S}|)$ and entropically unfavorable $(-\mathrm{T} \Delta \mathrm{S}>0)$. Comparison of charge-analogs of similar structure (e.g., Trp-OMe vs. N-AcTrp and TrpA vs. IPA) reveals that differences in free energy are due mostly to differences in the entropy of binding. For example, TrpA and IPA have statistically identical enthalpies of binding, but their entropies vary significantly and account for most of the difference in free energy. The same is true for Trp-OMe and N-AcTrp. This result is likely due to the influence of solvent on binding.

Charge-Mediated Peptide Recognition. The additional stability observed for the positively charged tryptophan derivatives led us to hypothesize that Q8 $\bullet \mathrm{MV}$ should bind to N-terminal tryptophan residues with higher affinity than C-terminal or internal tryptophan residues, thereby providing a basis for the recognition of specific peptides. To test this hypothesis, we studied a series of four tryptophan-containing peptides (Figure 3b): WGG (9), GWG (10), GGW (11), and GGWGG (12). WGG, with an N-terminal tryptophan residue, has a positive charge adjacent to the indole and is therefore analogous to Trp-OMe and TrpA. GGW, with a C-terminal tryptophan residue, has a negative charge 
adjacent to the indole and is therefore analogous to N-AcTrp and IPA. GWG places tryptophan at the internal position of the tripeptide. GGWGG serves as a control for GWG by separating the charges from the indole at distances that are more closely analogous to the distal charges on GGW and WGG.

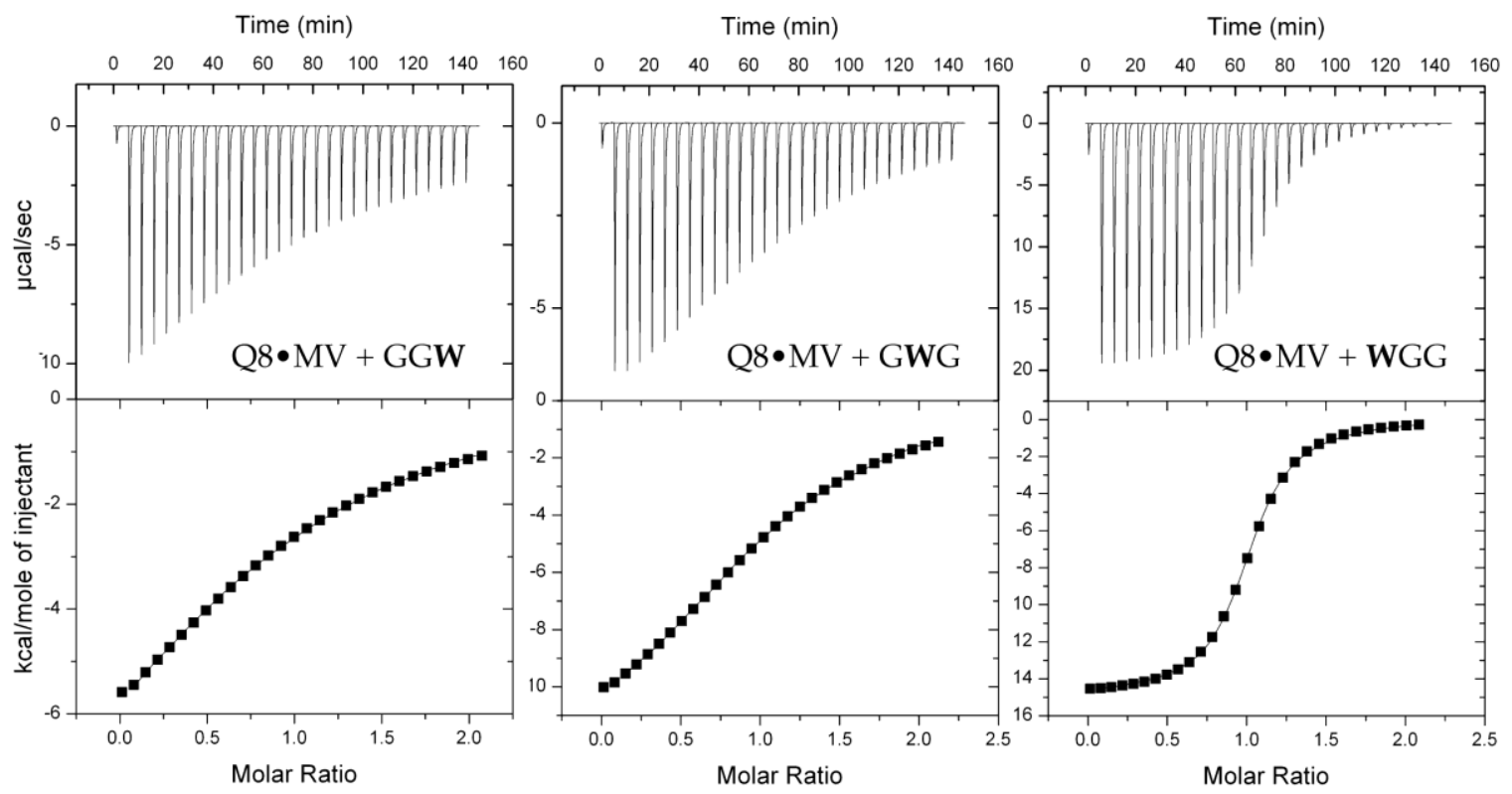

Figure 4. ITC data for the complexation of Q8 $\bullet$ MV with GGW (left), GWG (center), and WGG (right) at $27^{\circ} \mathrm{C}$ in $10 \mathrm{mM}$ sodium phosphate buffer, $\mathrm{pH}$ 7.0. WGG and GGW were titrated at 5 $\mathrm{mM}$ into a $0.5 \mathrm{mM}$ solution of Q8 $\bullet \mathrm{MV}$. GWG was titrated at $2 \mathrm{mM}$ into a $0.2 \mathrm{mM}$ solution of $\mathrm{Q} 8 \bullet \mathrm{MV}$. The top plot shows the raw data for power applied as a function of time. The integrated enthalpy values are plotted at bottom as a function of the molar ratio of

ITC was used to determine the thermodynamic parameters (Table 3) for the binding of $\mathrm{Q} 8 \bullet \mathrm{MV}$ to tryptophan-containing peptides 9 - 12. A 1:1 binding stoichiometry was observed in all experiments. The ITC data (Figure 4) show that $\mathrm{Q} 8 \bullet \mathrm{MV}$ binds to WGG with the highest affinity $\left(\mathrm{K}_{\mathrm{a}}=1.3 \times 10^{5} \mathrm{M}^{-1}\right)$, with $\sim 6$ fold selectivity over GWG $\left(\mathrm{K}_{\mathrm{a}}=2.1 \times 10^{4} \mathrm{M}^{-1}\right)$ and GGWGG $\left(\mathrm{K}_{\mathrm{a}}=2.5 \times 10^{4} \mathrm{M}^{-1}\right)$, 
and with $\sim 40$-fold specificity over GGW $\left(\mathrm{K}_{\mathrm{a}}=3.1 \times 10^{3} \mathrm{M}^{-1}\right) .{ }^{20}$ The presence of each ternary complex was confirmed by ESI-MS. All binding experiments were also carried out in the absence of Q8, and no indication of binding was observed; this result shows that binding affinity in the absence of $\mathrm{Q} 8$ is $<10^{3} \mathrm{M}^{-1}$. It should be noted that the high stability of the Q8 $\bullet \mathrm{MV} \bullet \mathrm{WGG}$ complex $(-7 \mathrm{kcal} / \mathrm{mol})$ is rare for a synthetic host in aqueous solution, ${ }^{21}$ and further supports the study of Q8 as a model for biomolecular receptors.

Table 3. Thermodynamic Binding Data for Q8 $\bullet \mathrm{MV}$ with Peptides of Tryptophan

\begin{tabular}{lcccrc}
\hline Guest & & $\begin{array}{c}\mathrm{K}_{\mathrm{a}}^{\mathrm{a}} \\
\left(\mathrm{M}^{-1}\right)\end{array}$ & $\begin{array}{c}\Delta \mathrm{G}^{\mathrm{b}} \\
(\mathrm{kcal} / \mathrm{mol})\end{array}$ & $\begin{array}{c}\Delta \mathrm{H}^{\mathrm{c}} \\
(\mathrm{kcal} / \mathrm{mol})\end{array}$ & $\begin{array}{c}-\mathrm{T} \Delta \mathrm{S}^{\mathrm{d}} \\
(\mathrm{kcal} / \mathrm{mol})\end{array}$ \\
\hline WGG & $\mathbf{( 9 )}$ & $1.3( \pm 0.3) \times 10^{5}$ & $-7.0( \pm 0.2)$ & $-14.8( \pm 0.5)$ & $7.8( \pm 0.5)$ \\
GWG & $\mathbf{( 1 0})$ & $2.1( \pm 0.1) \times 10^{4}$ & $-5.9( \pm 0.1)$ & $-11.4( \pm 0.7)$ & $5.5( \pm 0.8)$ \\
GGW & $\mathbf{( 1 1 )}$ & $3.1( \pm 0.4) \times 10^{3}$ & $-4.8( \pm 0.1)$ & $-8.8( \pm 1.3)$ & $4.0( \pm 1.4)$ \\
GGWGG & $\mathbf{( 1 2 )}$ & $2.5( \pm 0.2) \times 10^{4}$ & $-6.0( \pm 0.1)$ & $-12.1( \pm 0.1)$ & $6.1( \pm 0.2)$ \\
\hline
\end{tabular}

a Mean values measured from at least three ITC experiments at $27^{\circ} \mathrm{C}$ in $10 \mathrm{mM}$ sodium phosphate, $\mathrm{pH} 7.0$. Standard deviations are given in parentheses. ${ }^{b}$ Gibbs free energy values calculated from Ka values. Standard deviations for $\Delta \mathrm{G}$ values were calculated as the relative error observed in $\mathrm{K}_{\mathrm{a}}$, due to their relationship by a natural logarithm. ${ }^{c}$ Enthalpy values measured by ITC. ${ }^{d}$ Entropic contributions to $\Delta G$ calculated from Ka and $\Delta \mathrm{H}$ values.

As observed for the monomeric tryptophan derivatives, the peptide with a positive charge near the indole (WGG) binds Q8・MV with higher affinity than the peptide with a negative charge near the indole (GGW). In this series, however, the affinity of GWG for Q8 $\bullet \mathrm{MV}$ is approximately halfway between that of WGG and GGW. Table 4 ranks the binding constants for Q8•MV with all indole compounds and lists the specificities relative to GWG. Collectively, the data suggest that electrostatic charge near the indole is the key structural feature that governs recognition, thus supporting our hypothesis for charge-mediated peptide 
recognition. Moreover, within each group of positively or negatively charged guests, a second trend is apparent: Increasing molecular size increases complex stability. This trend is observed for both groups, albeit to a lesser extent for the negatively charged guests GGW, N-AcTrp, and IPA, and is likely related to hydrophobic interactions.

Table 4. Charge-Mediated Specificity

\begin{tabular}{lcccc}
\hline Guest & & Charge $^{\mathrm{a}}$ & $\log \mathrm{K}_{\mathrm{a}}$ & $\Delta\left(\log \mathrm{K}_{\mathrm{a}}\right)$ \\
\hline WGG & $\mathbf{( 9 )}$ & + & 5.1 & 0.8 \\
Trp-OMe & $\mathbf{( 5 )}$ & + & 4.8 & 0.5 \\
TrpA & $\mathbf{( 6 )}$ & + & 4.7 & 0.4 \\
Trp & $\mathbf{( 1 )}$ & +- & 4.6 & 0.3 \\
GGWGG & $\mathbf{( 1 2 )}$ & & 4.4 & 0.1 \\
GWG & $\mathbf{( 1 0 )}$ & & 4.3 & 0.0 \\
GGW & $(\mathbf{1 1})$ & - & 3.5 & -0.8 \\
N-AcTrp & $(\mathbf{7})$ & - & 3.5 & -0.8 \\
IPA & $\mathbf{( 8 )}$ & - & 3.4 & -0.9 \\
\hline
\end{tabular}

a Denotes formal charges immediately proximal to the indole ring.

Analysis of enthalpy and entropy values for the series (Table 3) of peptides shows again that binding is enthalpically driven and entropically unfavorable. Moreover, the data reveal that the enthalpy and entropy of binding increase in magnitude for a positive charge near the indole and decrease for a negative charge. This result could be explained by enthalpy-entropy compensation, in which an increased attraction between binding partners reduces their freedom of movement and results in a more favorable enthalpy at the cost of entropy. ${ }^{22}$ A binding model in which the positive charge on WGG interacts favorably with Q8 $\bullet \mathrm{MV}$ (perhaps at the carbonyl portal) and the 
negative charge on GGW interacts unfavorably with Q8 $\bullet$ MV would be consistent with this data. We cannot, however, determine the mechanism of binding on the basis of this data alone.

Spectroscopic Studies. In addition to the calorimetric studies described above, complex formation was also examined by changes in the UV-visible, fluorescence, and NMR spectra. These results are presented here, using WGG as an example.

$\mathrm{UV}$-visible absorption spectra (at $25^{\circ} \mathrm{C}$ in $10 \mathrm{mM}$ sodium phosphate, $\mathrm{pH}$ 7.0) were obtained for compounds $\mathbf{1}$ and $\mathbf{5 - 1 2}$ in the absence and presence of $\mathrm{MV}$ and $\mathrm{Q} 8 \bullet \mathrm{MV}$. Figure 5 shows a representative overlay of the three spectra for WGG at 0.025 and $1.0 \mathrm{mM}$ concentrations. The characteristic $\pi-\pi^{*}$ transition for the indole group blue-shifts by $\sim 20 \mathrm{~nm}$ in the presence of $\mathrm{MV}$ or Q8 $\bullet \mathrm{MV}$. What is more interesting is the growth of a new absorbance band centered at $\sim 350 \mathrm{~nm}$ in the presence of $\mathrm{MV}$ and at $\sim 420 \mathrm{~nm}$ in the presence of Q8 $\bullet \mathrm{MV}$. As observed by Kim and coworkers for $\mathrm{Q} 8 \bullet \mathrm{MV} \bullet \mathrm{HN},{ }^{13}$ these new transitions indicate the formation of a charge-transfer complex between the indole and MV. The redshift of the charge-transfer band in the presence of $\mathrm{Q} 8 \bullet \mathrm{MV}$ versus $\mathrm{MV}$ alone shows that Q8 enhances the charge-transfer interaction. ${ }^{19}$ 


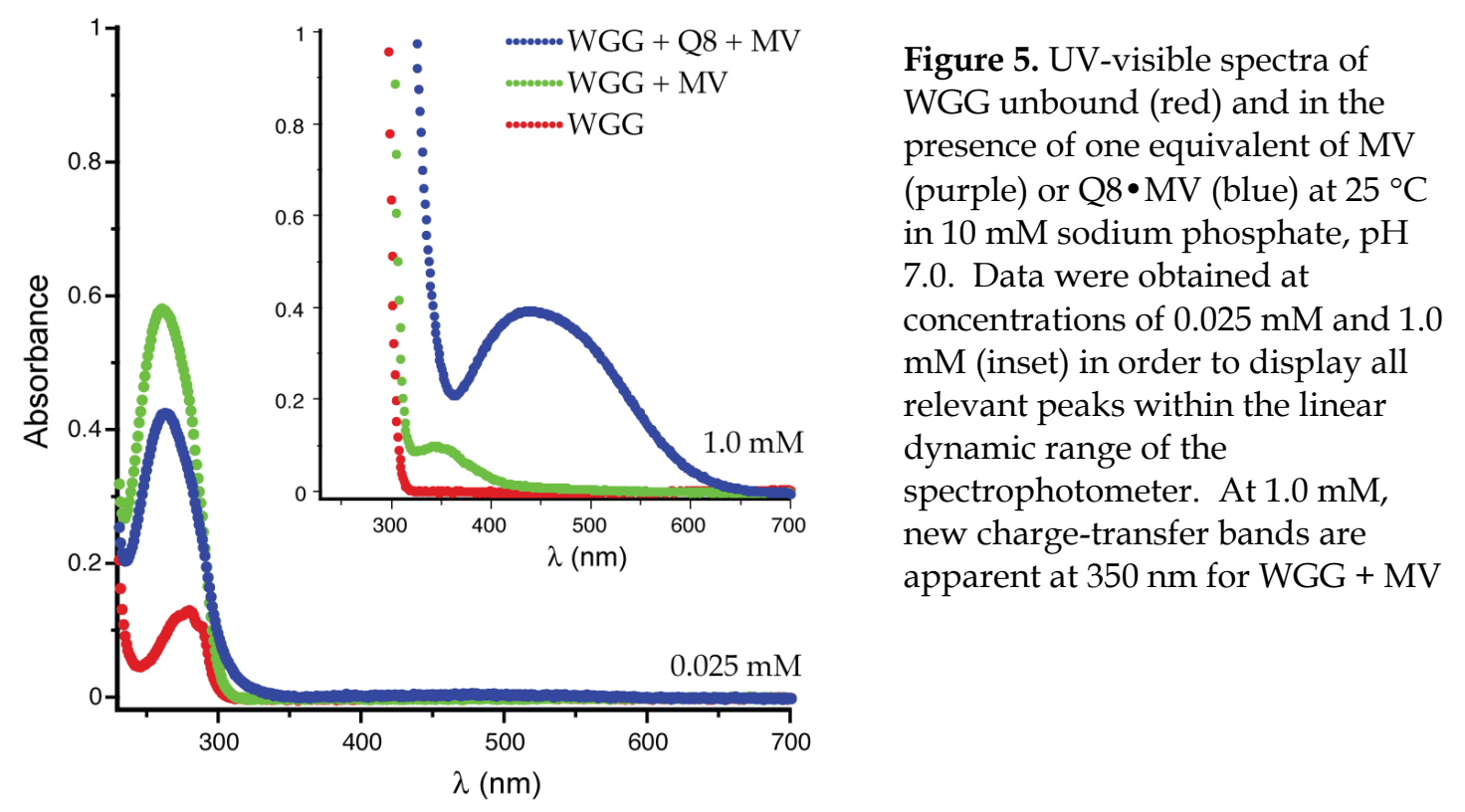

We measured values for the wavelength of maximum absorbance $\left(\lambda_{\max }\right)$

and the molar absorptivity $\left(\varepsilon_{\max }\right)$ at this wavelength for the charge-transfer band of each $\mathrm{Q} 8 \bullet \mathrm{MV} \bullet \mathrm{X}$ complex, taking into account the fraction of ternary complex available at the working concentration $(500-600 \mu \mathrm{M})$ using the equilibrium association constants for the formation of $\mathrm{Q} 8 \bullet \mathrm{MV}$ and $\mathrm{Q} 8 \bullet \mathrm{MV} \bullet \mathrm{X}$. The energy and intensity of the charge-transfer transition in each ternary complex was relatively consistent among all indole derivatives in this study $\left(\lambda_{\max }=420-450\right.$ $\left.\mathrm{nm} ; \varepsilon_{\max }=300-600 \mathrm{~cm}^{-1} \mathrm{M}^{-1}\right)$. This result supports a consistent mechanism of binding where the indole group and MV are stacked in a charge-transfer complex that is stabilized by Q8. These results are consistent with data from Kim and coworkers, ${ }^{13}$ who showed that the binding of $\mathrm{HN}$ to $\mathrm{Q} 8 \bullet \mathrm{MV}$ is accompanied by the appearance of a charge-transfer band in the visible spectrum, and that the $\mathrm{HN}$ and MV rings are stacked face-to-face inside the Q8 cavity. The increase in 
visible absorbance on binding provides an excellent handle for the development of optical sensors for specific peptides.

Fluorescence emission spectra (at $25^{\circ} \mathrm{C}$ in $10 \mathrm{mM}$ sodium phosphate, $\mathrm{pH}$ 7.0) were obtained for all indole compounds in the absence and presence of MV and Q8 $\bullet \mathrm{MV}$. Figure 6 shows a representative overlay of the three spectra for WGG at $12.5 \mu \mathrm{M}$ concentration. As expected for a charge-transfer interaction, 19 the presence of the acceptor reduces the fluorescence intensity of the donor. At $12.5 \mu \mathrm{M}$, the presence of MV alone has a significant influence and quenches indole fluorescence by $14 \%$. In the presence of $\mathrm{Q} 8 \bullet \mathrm{MV}$, however, the effect is much greater, and fluorescence is quenched by $60 \%$. A similar result was observed by Kim and coworkers for the Q8 $\bullet \mathrm{MV} \bullet \mathrm{HN}$ system..$^{13}$

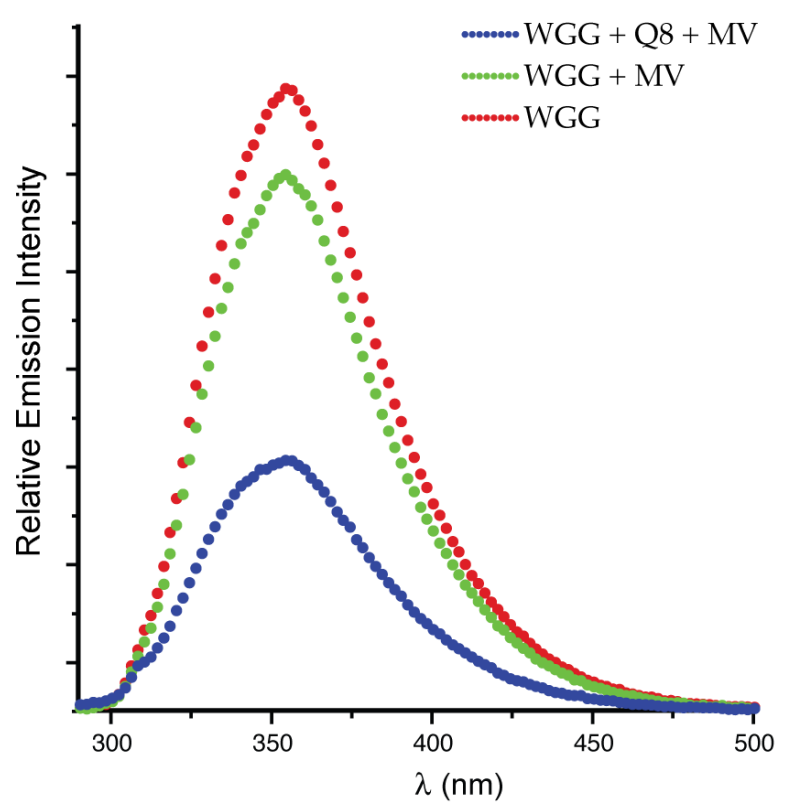

Figure 6. Fluorescence emission spectra for WGG unbound (red) and in the presence of one equivalent of MV (purple) or $\mathrm{Q} 8 \bullet \mathrm{MV}$ (blue). All spectra were obtained with excitation at 279 $\mathrm{nm}$ at $25^{\circ} \mathrm{C}$ at a concentration of $12.5 \mu \mathrm{M}$ in $10 \mathrm{mM}$ sodium phosphate, $\mathrm{pH}$ 7.0. Significant quenching of indole fluorescence is apparent in the 
We plotted the quenching induced by $\mathrm{Q} 8 \bullet \mathrm{MV}(\%$ quenched) as a function of the fraction of complex available (\% bound) at $50 \mu \mathrm{M}$ for all indole derivatives studied here (Figure 7). The data fit reasonably well to a straight line, showing a consistent degree of quenching among the various compounds. The y-intercept in this plot is, however, substantially greater than 0 . Figure 5 shows that there is significant absorbance in the $300-500 \mathrm{~nm}$ region, which is the range of the spectrum monitored for fluorescence excitation and emission. This overlap suggests that the additional quenching we observe is due to additional absorption of the excitation and emission light by molecules in the sample. The consistency in fluorescence data observed among the various indole derivatives further supports a common mode of binding, whereby Q8 promotes close interaction between indole and MV. The quenching of fluorescence on binding provides an additional handle for the development of optical sensors for specific peptides. 


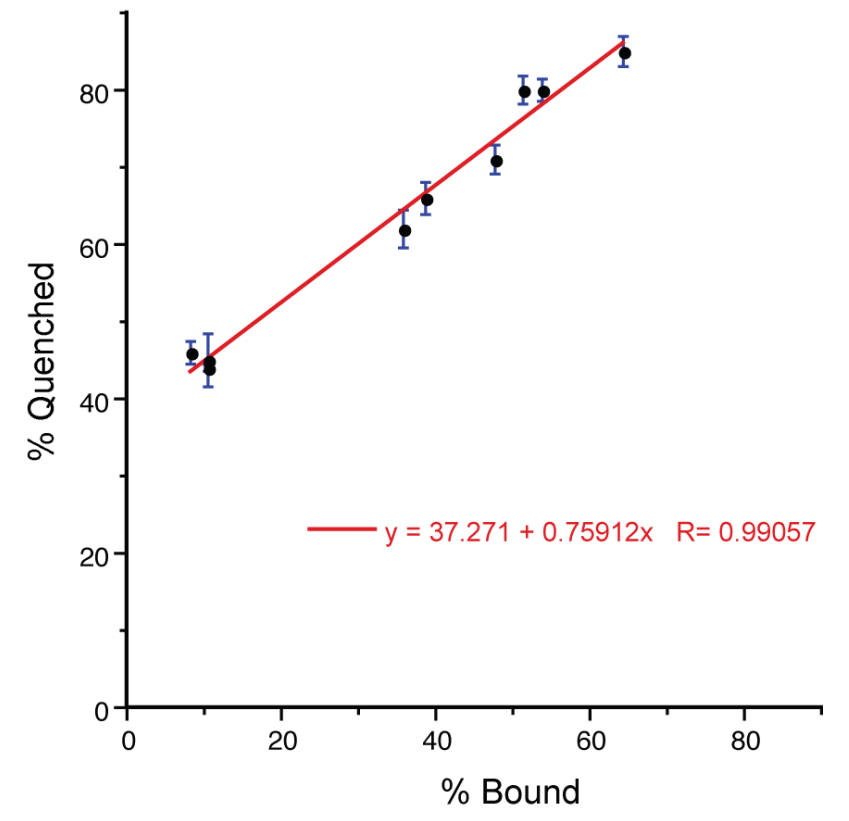

Figure 7. Plot of the extent of fluorescence quenching observed at $50 \mu \mathrm{M}$ in the presence of Q8 $\bullet \mathrm{MV}$ for indole derivatives $\mathbf{1}$ and $\mathbf{5}$ - 12. Data were obtained as described in Figure 6. \% Bound was calculated as the fraction of ternary complex present at $50 \mu \mathrm{M}$ based on the equilibrium association constants determined by ITC. The linear fit observed suggests a common mode of quenching and, thus, binding among the indole derivatives; this result further suggests that fluorescence quenching is a promising handle for the

${ }^{1} \mathrm{H}$ NMR spectra in unbuffered deuterium oxide were obtained at $25{ }^{\circ} \mathrm{C}$ for each indole derivative by itself and in the presence of an equivalent of MV or Q8 $\bullet$ MV. Representative spectra for WGG are shown in Figure 8. It is clear that the presence of MV alone does not alter the spectrum of WGG, but the presence of Q8 $\bullet$ MV changes the spectrum of WGG considerably. The extensive broadening and change in chemical shift of the WGG and MV peaks in the presence of Q8, combined with the knowledge that a charge-transfer interaction is present between the two aromatic guests, again suggests that the MV and indole groups are bound inside the cavity of Q8, as in the case of the $\mathrm{Q} 8 \bullet \mathrm{MV} \bullet \mathrm{HN}$ system. This result is consistent among the indole-based compounds in this study (see Supporting Information). Peak broadening combined with the presence of only one set of peaks at various stoichiometric ratios ratios (data not shown) indicates a rapid exchange process that would 
complicate the study of the intermolecular interactions under these conditions by multidimensional NMR methods.

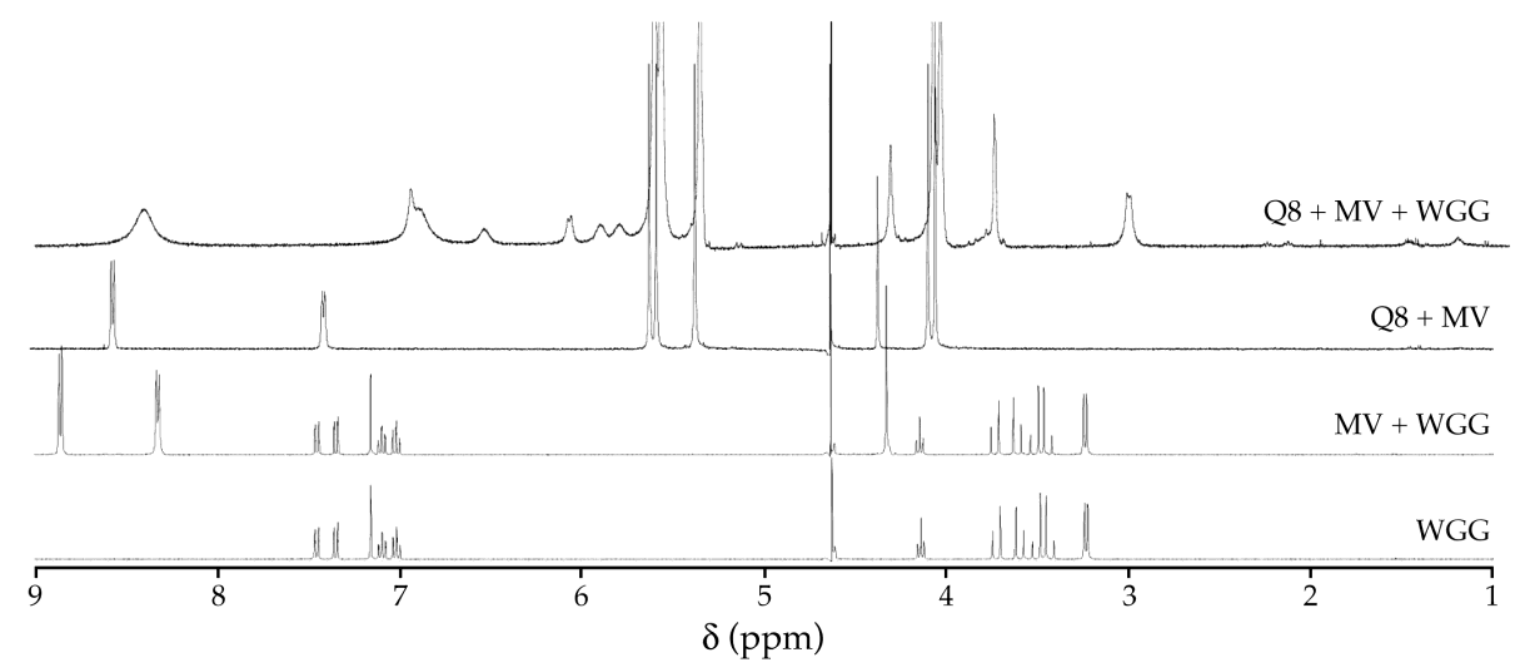

Figure 8. ${ }^{1} \mathrm{H}$ NMR spectra at $25{ }^{\circ} \mathrm{C}$ in deuterium oxide for various combinations of WGG, MV, and Q8. Mixtures are equimolar, and concentrations were 1-3 mM. The strong correlation between peaks in the WGG and MV WGG spectra show that MV does not significantly bind to WGG at these concentrations. The peaks of WGG and MV shift by up to $2 \mathrm{ppm}$ in the presence of Q8, indicating the close interaction of $\mathrm{MV}$ and $\mathrm{WGG}$ with $\mathrm{Q} 8$. The poor resolution of the $\mathrm{Q} 8 \cdot \mathrm{MV} \cdot \mathrm{WGG}$ spectrum makes it difficult to assign all protons unambiguously.

Collectively, the thermodynamic and spectroscopic data presented here, as well as prior work by Kim and coworkers, ${ }^{13}$ support a model for binding in which the MV and indole rings bind face-to-face inside the cavity of Q8, and in which the ternary complex is stabilized by a charge-transfer interaction between indole and MV, and by hydrophobic interactions. The similarities observed for UV-visible absorptivity, absorbance wavelength, extent of fluorescence quenching, and NMR peak broadening strongly support a similar mode of binding for all indole derivatives. Given the consistent inclusion of indole within 
the $\mathrm{Q} 8$ cavity, it is plausible that $\mathrm{Q} 8 \bullet \mathrm{MV}$ recognizes WGG > GWG > GGW primarily on the basis of electrostatic charge. A detailed explanation of these phenomena awaits high-resolution structural information.

\section{Conclusions}

This paper examines the potential for the $\mathrm{Q} 8 \bullet \mathrm{MV}$ complex to recognize specific amino acids and peptides in aqueous solution. Using a combination of calorimetric and spectroscopic methods, we have shown that the Q8 $\bullet \mathrm{MV}$ complex is an effective host for high-affinity, selective peptide recognition in aqueous solution, and that selectivity is mediated by electrostatic charge. This host system is important and, in fact, rare because it can bind to biochemically relevant guests with high affinity in a biochemically relevant environment. ${ }^{1,2}$ In addition, these studies provide quantitative thermodynamic data for the reversible binding processes of Q8 that support the many ongoing studies of Q8 as a tool in supramolecular chemistry and as a model for biomolecular receptors.

\section{Experimental Details}

Materials. The following commercial reagents of analytical or higher purity grade were used without further purification: deuterium oxide (Cambridge Isotope Laboratories); H-Trp-Gly-Gly-OH (WGG), H-Gly-Trp-Gly- 
$\mathrm{OH}$ (GWG), and H-Gly-Gly-Trp-OH (GGW) (Bachem); sodium phosphate (monobasic and dibasic), L-tryptophan (Trp), N-acetyl-L-tryptophan (N-AcTrp) (Sigma); 3-indolepropionic acid (IPA), tryptamine hydrochloride (TrpA), methyl viologen dichloride hydrate (MV), L-tryptophan methyl ester hydrochloride (Trp-OMe) (Aldrich); Cucurbit[8]uril (Q8) was synthesized by the group of Dr. Anthony Day (University of New South Wales, Australia) and purchased from Unisearch. Water was obtained from a Barnstead Nanopure Infinity Ultrapure water system $(18 \mathrm{M} \Omega-\mathrm{cm})$.

A stock solution of $1.0 \mathrm{M}$ sodium phosphate buffer was adjusted to $\mathrm{pH} 7.0$ and sterile filtered. The $\mathrm{pH}$ was checked periodically. With the exception of the NMR experiments, which were run in deuterium oxide, all binding experiments described here were carried out in $10 \mathrm{mM}$ phosphate buffer, which was made as needed by diluting the $1 \mathrm{M}$ stock. Fresh analyte solutions were prepared every couple of days and were thoroughly dissolved by heating at $60^{\circ} \mathrm{C}$ and, if necessary, by ultrasonication. All analytes were massed to $\pm 0.1 \mathrm{mg}$ with an accuracy of at least three significant digits. The purities of Q8 and MV were determined by ${ }^{1} \mathrm{H}$ NMR using freshly distilled tert-butyl alcohol as reference. Purities of other analytical reagents were determined by titration.

Isothermal Titration Calorimetry (ITC). Titration experiments were carried out in $10 \mathrm{mM}$ sodium phosphate buffer ( $\mathrm{pH} 7.0)$ at $27^{\circ} \mathrm{C}$ on a VP-ITC calorimeter from Microcal, Inc (http://www.microcalorimetry.com). In a typical 
experiment, the $\mathrm{Q} 8 \bullet \mathrm{MV}$ was in the sample cell at a concentration of $0.1-1.0$ $\mathrm{mM}$, and the guest was in the injection syringe at a concentration of $1.0-10 \mathrm{mM}$. The titration schedule consisted of $28-40$ consecutive injection of $2-10 \mu \mathrm{L}$ with at least a $200 \mathrm{~s}$ interval between injections. Heats of dilution, measured by titrating beyond saturation, were subtracted from each data set. All solutions were degassed prior to titration. The data were analyzed using Origin software and fit well to the 1:1 binding model supplied with the software.

It is important to note that the initial concentration of $\mathrm{Q} 8 \bullet \mathrm{MV}$ in a titration is influenced by equilibrium constant for the formation of Q8 $\bullet \mathrm{MV}$ and by the working concentration. For example, at $0.5 \mathrm{mM}$, the fraction of $\mathrm{Q} 8 \bullet \mathrm{MV}$ present is $95.3 \%$. By increasing the concentration of MV by 10 -fold, however, the fraction of $\mathrm{Q} 8 \bullet \mathrm{MV}$ increases to $99.9 \%$. The dynamic effect of this equilibrium would significantly complicate a rigorous analysis of the ITC data, but should, at the most, effect the results by $<5 \%$. To examine the actual effect, we carried out ITC titrations with a 10-fold excess of MV and found that the values obtained overlapped to within $5 \%$ of those obtained at a 1:1 Q8 $\bullet \mathrm{MV}$ ratio. Therefore, we ignore this effect for the data presented here.

Spectroscopy. ${ }^{1} \mathrm{H}$ NMR spectra were collected in deuterium oxide on a Varian Inova $400 \mathrm{MHz}$ spectrometer at $25^{\circ} \mathrm{C}$ using a presaturation pulse to suppress the signal from residual protiated solvent. UV-visible spectra were obtained at $25^{\circ} \mathrm{C}$ for all samples at a concentration of $0.5-0.6 \mathrm{mM}$ in $10 \mathrm{mM}$ 
sodium phosphate buffer (pH 7.0) using Varian Cary 100 Bio and Hitachi U-3000 spectrophotometers. Molar absorptivities for the charge-transfer band in the $\mathrm{Q} 8 \bullet \mathrm{MV} \bullet \mathrm{X}$ complexes were determined at the wavelength of maximum absorbance, using the equilibrium constant determined by ITC to account for the mole fraction of complex present at the working concentration. Fluorescence emission spectra were obtained at $25^{\circ} \mathrm{C}$ in $10 \mathrm{mM}$ sodium phosphate buffer $(\mathrm{pH}$ 7.0) with a PTI QM-4 spectrofluorometer equipped with a Xe arc lamp and photomultiplier tube, exciting at $279 \mathrm{~nm}$, with 3 and $4 \mathrm{~nm}$ slit widths for the excitation and emission monochrometers, respectively, and a step size of $2 \mathrm{~nm}$. Fluorescence intensities were determined by integration.

Acknowledgements. We thank Brian Halbert for synthesizing GGWGG, Prof Chris Pursell for many helpful discussions, and Prof Lyle Isaacs for inspiration. We gratefully acknowledge the donors of the American Chemical Society Petroleum Research Fund (PRF\#42220-GB4) and Trinity University for research support, the Howard Hughes Medical Institute for an undergraduate fellowship to NDB, and the Keck Foundation for generous support to Trinity University that provided the mass spectrometer, titration calorimeter, and spectrofluorometer used in this study. 
Supporting Information Available: Representative ITC, NMR, and mass spectrometry data for compounds $\mathbf{1}$ and 5-12 in complex with Q8 $\bullet \mathrm{MV}$. ITC data for the formation of Q8・MV. Synthesis and characterization of GGWGG. 


\section{References}

(1) Peczuh, M. W.; Hamilton, A. D. Chem. Rev. 2000, 100, 2479-2493.

(2) For selected, recent examples, see: (a) Schmuck, C.; Geiger, L. J. Am. Chem. Soc. 2005, Available ASAP online. (b) Tashiro, S.; Tominaga, M.; Kawano, M.; Therrien, B.; Ozeki, T.; Fujita, M. J. Am. Chem. Soc. 2005, 127, 4546-4547. (c) Schmuck, C.; Geiger, L. J. Am. Chem. Soc. 2004, 126, 8898-8899. (d) Wright, A. T.; Anslyn, E. V. Org. Lett. 2004, 6, 1341-1344. (e) Escuder, B.; Rowan, A. E.; Feiters, M. C.; Nolte, R. J. M. Tetrahedron 2004, 60, 291-300. (f) Jensen, K. B.; Braxmeier, T. M.; Demarcus, M.; Frey, J. G.; Kilburn, J. D. Chem. Eur. J. 2002, 8, 1300-1309. (g) Sirish, M.; Schneider, H.-J. Chem. Comm. 1999, 907-908. (h) Allott, C.; Adams, H.; Hunter, C. A.; Thomas, J. A.; Bernad, P. L., Jr.; Rotger, C. Chem. Comm. 1998, 2449-2450. (i) Breslow, R.; Yang, Z.; Ching, R.; Trojandt, G.; Odobel, F. J. Am. Chem. Soc. 1998, 120, 3536-3537.

(3) For selected, recent examples, see: (a) Mandl, C. P.; Konig, B. J. Org. Chem. 2005, 70, 670-674. (b) Tsubaki, K.; Kusumoto, T.; Hayashi, N.; Nuruzzaman, M.; Kaoro, F. Org. Lett. 2002, 4, 2313-2316. (c) Ojida, A.; Mito-oka, Y.; Inoue, M.; Hamachi, I. J. Am. Chem. Soc. 2002, 124, 6256-6258. (d) Ait-Haddou, H.; Wiskur, S. L.; Lynch, V. M.; Anslyn, E. V. J. Am. Chem. Soc. 2001, 123, 11296-11297. (e) Hossain, M. A.; Schneider, H.-J. J. Am. Chem. Soc. 1998, 120, 11208-11209. (f) Still, W. C. Acc. Chem. Res. 1996, 29, 155-163. (g)Wagner, H.; Still, W. C.; Chen, C.-T. Science 1998, 279, 851-853.

(4) Kim, J.; Jung, I.-S.; Kim, S.-Y.; Lee, E.; Kang, J.-K.; Sakamoto, S.; Yamaguchi, K.; Kim, K. J. Am. Chem. Soc. 2000, 122, 540-541.

(5) Lee, J. W.; Samal, S.; Selvapalam, N.; Kim, H.-J.; Kim, K. Acc. Chem. Res. 2003, 36, 621-630.

(6) Behrend, R.; Meyer, E.; Rusche, F. Liebigs Ann. Chem. 1905, 339, 1-37.

(7) (a) Mock, W. L.; Shih, N.-Y. J. Org. Chem. 1983, 48, 3618-3619. (b) Mock, W. L.; Shih, N.-Y. J. Org. Chem. 1986, 51, 4440-4446. (c)Mock, W. L.; Shih, N.-Y. J. Am. Chem. Soc. 1988, 110, 4706-4710. (d) Buschmann, H.-J.; Cleve, E.; Schollmeyer, E. Inorg. Chim. Acta 1992, 193, 93-97. (e) Buschmann, H.-J; Schollmeyer, E.; Mutihac, L. Thermochim. Acta 2003, 399, 203-208.

(8) (a) Day, A. I.; Arnold, A. P.; Blanch, R. J.; Snushall, B. J. Org. Chem. 2001, 66, 8094-8100. (b) Lagona, J.; Fettinger, J. C.; Isaacs, L. Org. Lett. 2003, 5, 3745-3747. (c) Burnett, C. A.; Lagona, J.; Wu, A.; Shaw, J. A.; Coady, D.; Fettinger, J. C.; Day, A. I.; Isaacs, L. Tetrahedron 2003, 59, 1961-1970.

(9) Marquez, C.; Hudgins, R. R.; Nau, W. M. J. Am. Chem. Soc. 2004, 126, 5806-5816.

(10) (a) Ong, W.; Gomez-Kaifer, M.; Kaifer, A. E. Org. Lett. 2002, 4, 1791-1794. (b) Ong, W.; Kaifer, A. Angew. Chem. Int. Ed. 2003, 42, 2164-2167. (c) Ong, W.; Kaifer, A. E. J. Org. Chem. 2004, 69, 1383-1385. (d) Moon, K.; Kaifer, A. E. Org. Lett. 2004, 6, 185-188. (e) Sindelar, V.; Moon, K.; Kaifer, A. E. Org. Lett. 2004, 6, 2665-2668.

(11) Kim, H.-J.; Jeon, W. S.; Ko, Y. H.; Kim, K. Proc. Natl. Acad. Sci. USA 2002, 99, 5007-5011. 
(12) (a) Blanch, R. J.; Sleeman, A. J.; White, J. T.; Arnold, A. P.; Day, A. I. Nano Lett. 2002, 2, 147-149. (b) Wagner, B. D.; Stojanovic, N.; Day, A. I.; Blanch, R. J. J. Phys. Chem. B 2003, 2003, 10741-10756.

(13) Kim, H.-J.; Heo, J.; Jeon, W. S.; Lee, E.; Kim, J.; Sakamoto, S.; Yamaguchi, K.; Kim, K. Angew. Chem. Int. Ed. 2001, 40, 1526-1529.

(14) (a) Kim, S.-Y.; Jung, I.-S.; Lee, E.; Kim, J.; Sakamoto, S.; Yamaguchi, K.; Kim, K. Angew. Chem. Int. Ed. 2001, 40, 2119-2121. (b) Lee, J. W.; Kim, K.; Choi, S. W.; Ko, Y. H.; Sakamoto, S.; Yamaguchi, K.; Kim, K. Chem. Comm. 2002, 2692-2693. (c) Jeon, Y. J.; H., K.; Jon, S.; Selvapalam, N.; Oh, D. H.; Seo, I.; Park, C.-S.; Jung, S. R.; Koh, D.-S.; Kim, K. J. Am. Chem. Soc. 2004, 126, 15944-15945. (d) Moon, K.; Grindstaff, J.; Sobransingh, D.; Kaifer, A. E. Angew. Chem. Int. Ed. 2004, 43, 5496-5499. (e) Ziganshina, A.; Ko, Y. H.; Jeon, W. S.; Kim, K. Chem. Comm. 2004, 806-807. (f) Ko, Y. H.; Kim, K.; Kang, J.-K.; Chun, H.; Lee, J. W.; Sakamoto, S.; Yamaguchi, K.; Fettinger, J.; Kim, K. J. Am. Chem. Soc. 2004, 126, 1932-1933. (g) Kim, K.; Kim, D.; Lee, J. W.; Ko, Y. H.; Kim, K. Chem. Comm. 2004, 848-849. (h) Jeon, W. S.; Kim, E.; Ko, Y. H.; Hwang, I.; Lee, J. W.; Kim, S.Y.; Kim, H.-J.; Kim, K. Angew. Chem. Int. Ed. 2005, 44, 87-91.

(15) (a) Jon, S. Y.; Ko, Y. H.; Park, S. H.; Kim, H.-J.; Kim, K. Chem. Comm. 2001, 1938-1939. (b) Ramamurthy, V. Org. Lett. 2005, 7, 529-532.

(16) US Patent: Kim, K.; Kim, J.; Jung, I.-S.; Kim, S.-Y.; Lee, E.; Kang, J.-K.; Pohang University of Science and Technology Foundation, 2000.

(17) Jeon, W. S.; Kim, H.; Lee, C.; Kim, K. Chem. Comm. 2002, 1828-1829.

(18) This value is significantly higher than that reported by Kim and coworkers $(1.1 \mathrm{x}$ $\left.10^{5} \mathrm{M}^{-1},{ }^{17}\right)$. The basis for this discrepancy is unclear.

(19) Foster, R. Organic Charge-Transfer Complexes; London New York Academic Press: New York, 1969.

(20) We also studied at GGG as a control for the presence of a tryptophan and, as expected, observed no binding to $\mathrm{Q} 8 \bullet \mathrm{MV}$ by ITC.

(21) Houk, K. N.; Leach, A. G.; Kim, S. P.; Zhang, X. Angew. Chem. Int. Ed. 2003, 42, 4872-4897.

(22) Williams, D. H.; Stephens, E.; O'Brien, D.; Zhou, M. Angew. Chem. Int. Ed. 2004, 43, 6596-6616. 


\section{GRAPHICAL ABSTRACT}

$$
\begin{aligned}
& +\mathrm{X} \underset{\mathrm{H}_{2} \mathrm{O}, \mathrm{PH} 7.0}{\stackrel{\mathrm{K}=10^{3}-1 \mathrm{M}^{-1}}{.}}
\end{aligned}
$$

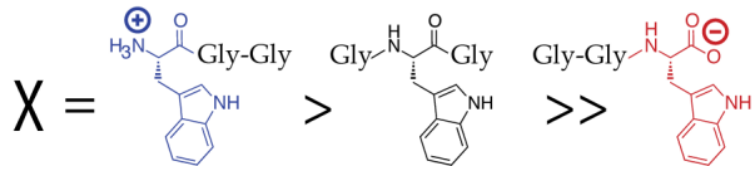

